\title{
Interactive Installation Design to Enhance Audience Immersion and Informational Behaviour
}

\author{
Michaela Buchtová \\ Informational Science and Librarianship, Faculty of Art, \\ Charles University in Prague, U Krize 8, Prague-Jinonice, Czech Republic \\ michaela. buchtova@ff.cuni.cz
}

\begin{abstract}
The paper presents a technical and dramaturgical concept of two interactive installations proposing a complex dramaturgic approach to physically and emotionally immerse an audience. The concept was firstly presented as "Memorial for survivors and victims of holocaust" in 2011 in Prague, Czech Republic. The first installation is based on a technique of life illusion applied on a life-size statue, while using a combination of video portrait and video mapping techniques. The second installation offers an interactive presentation of historical photos and videos. By physical movement, an audience enters a visual 3D space with multimedia gallery arranged in historical order. The dramaturgy of both installations depends on presence and active movement of an audience, and aims to create an immersive space and personal relationship to presented story. The human-computer interaction (HCI) system was developed to propose alternative forms for active and/or passive informational behaviour of public museum exhibits and educational projects.
\end{abstract}

Keywords: Interactive museum, Immersive installation, Video mapping, Kinect.

\section{$1 \quad$ Introduction}

Two installations presented here were created to propose an innovative approach to interactive installation dramaturgy. Moreover we aimed to offer a platform which can be used and adapted by museums or galleries to create immersive environments supporting an audience experience and learning through intuitive elements for informational seeking behaviour. Our intention was to present an installation which immerses an audience into the story, and creates a personal relationship with a viewer. Some authors [2] additionally claim that emotional engagement can stimulate willingness to future informational seeking and learning activities. By implementing various interactive elements, both installations emphasize immersive and deeply personal experience.

The technical concept of two installations ("Timeline" and "Talking statue") was firstly presented as "Memorial for survivors and victims of holocaust" and brought a story of Marketa Novakova, a woman who went through ghetto Theresienstadt and extermination camp Auschwitz-Birkenau. 
While creating the interactive and technical concept we got inspired by our longterm collaboration with French artist Dominik Barbier and mainly by his scenography of museum "Mémorial de la Marseillaise" in Marseille [5]. There he used an inside video mapping on walls and on statues of main French revolution partakers. Our first installation - temporary called "talking statue" - was created by Kristof Slussareff with consultations with Dominik Barbier. The interactive user interface and overall dramaturgy of both pieces was built mainly upon interactive elements using a motion sensing hardware Kinect. The interface was built upon NxGraphics [4], multimedia framework software developed by Stephane Kyles for projects using 3D visualization, audiovisual materials and Kinect controller.

\section{$2 \quad$ Life Illusion}

In the first installation - "talking statue" - we have built the interactive principles on a life-size statue (more precisely a bust) in combination with classic video-portrait. We got inspired by the ancient Greeks, who never left their statues white, but they covered them with bright colours instead - they drew an orange coloured skin and clothing [6]. Therefore we manufactured a bust of Marketa Novakova, on which we mapped a video of Marketa telling her life story closely connected with her life in extermination camp Auschwitz-Birkenau. Literary speaking, we "let the statue talk". The video mapping was done real time with software Adobe After Effects [1], the audio was recorded during several personal meetings with Marketa, in the installation is used a 6 minutes long record.
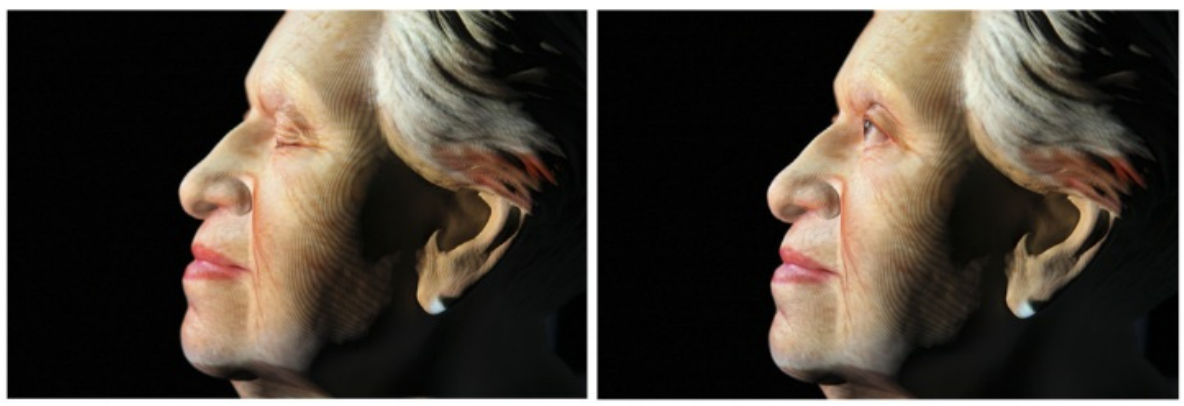

Fig. 1. Video mapping on the bust - effect of opening eyes

To enhance a personal engagement of audience, we added interactive elements reacting on mere presence of a viewer. In a sector of circle with approximate radius of three meters there is an interactive zone built upon Kinect. A viewer entering the interactive zone "awakens" the sculpture which tells its story in person. The audio rec-ord of Marketa's narration starts and Marketa's eyes open and blink (video mapping). While the viewer moves away from the interactive zone, the statue falls silent and white. As in absence of an active listener, stories of our past remain quietly forgotten. 


\section{Timeline}

The second interactive installation set nearby proposed additional information and embedded Marketa's testimony in global historical context. The installation called "Timeline" is basically a video projection using visual 3D space to create an optic illusion of physical distance. It allows audience to "travel in time" and seek in historical material by a mere movement. A multimedia presentation on projection consists of historical audiovisual material, mainly sequences of photos in loops and short videos with explanatory texts. Moving towards or away from the multimedia presentation, a viewer depicts historical events of the years $1922-2011$ and the photos or videos are showed in front.

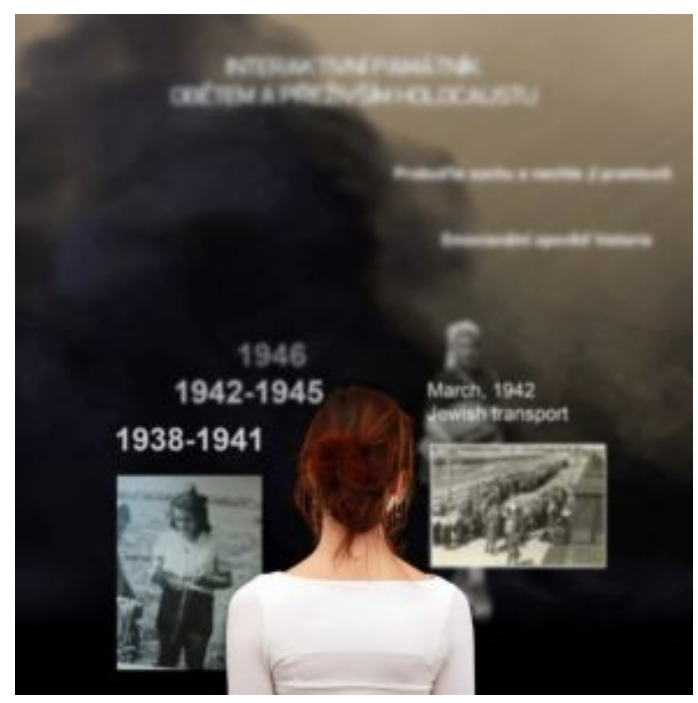

Fig. 2. Illustration of Timeline Installation

To strengthen the audience's immersion and physical illustration of "moving in history", as the presentation was inherited in 3D space, the audiovisual material from older time needs to be discovered by movement further to the presentation. On the floor there is a line highlighting historical periods so an audience can easily control the multimedia presentation and search information or material needed.

\section{Audience Feedback, Future Opportunities}

A technique of life illusion applied on the statue has shown as the key element while many people stayed stunned by a plasticity and vividness of bust visage and narration. According to audience comments, the interactive zone, which immediately reacts on a viewer's presence and leaving away, creates very personal relation with the story told by the statue. In the same way, the "Timeline" was appreciated because of its 
immersive 3D space. Both installations won a price of "The best interactive project built on Kinect" [3], audience decided about the winner.

Both installations can serve as a platform adaptable to other content and thematic. We used the platform to present a story of holocaust while "Talking statue" presented the history through a real testimony of one survivor and "Timeline" depicted the social and historical context by interactive audiovisual collage of real documents. The content, video mapping and statue can be changed, thus the platform can be used in museums and galleries. It brings a new interactivity and personal experience while reacting on the audience presence and movement.

Acknowledgements. The project was supported by Grant Agency of Charles University in Prague - project no. 5810/2012 "Digital Technologies in Education: Specification of the elements positively affecting learning and information behaviour".

The interactive installations were created with a support of non-profit organization „M77 - Arts, Digital Creation \& Training“: Kristof Slussareff (scenography, video), Stephan Kyles (programer, new media artist), Michael Gimenez (scenography, graphics), Stanislav Kokoška (historian, supervision), Michaela Buchtová (dramaturgy, project management). In collaboration with contemporary artist Dominik Barbier (Fearless Medi@terranée, France, www.fearless.fr), Foundation for Holocaust Victims (www.fondholocaust.cz), Post Bellum (www.postbellum.cz), Prague College (www.praguecollege.cz) and National Archive (www.nacr.cz).

\section{References}

1. Adobe: Adobe After Effects ${ }^{\circledR}$ (Version CS5) (Computer software)

2. Fredericks, J.A., Blumenfeld, P.C., Paris, A.H.: School engagement: Potential of the concept, state of the evidence. Review of Educational Research 74, 59-109 (2004)

3. Kovalík, J.: Jak jsme hackovali Kinect. Datarama online magazine Aktualne.cz (January 12, 2012) http://datarama.aktualne.centrum.cz/clanek. phtml ?id=723589 (ac-cessed: April 3, 2012)

4. Kyles, S.: NxGraphics (Computer software), http://code.google.com/p/subnetworks / source/browse/\#svn\%2Ftru nk2 FNxGraphics\%2FNxGraphicsSdk2 FNxVideo (accessed: April 3, 2012)

5. Mémorial de la Marseillaise. Museum paresentation, http://www. vertmarine.com/memorial-marseillaise-marseille-13/ (accessed: April 3, 2012)

6. Rosenthal, E. (ed.): Gods in Color: Painted Sculpture of Classical Antiquity. Harvard university Art Museums (2007) 